\title{
Acoustic Studies of Preferential Solvation of Tetraalkylammonium Salts in Dimethylsulfoxide + Methanol Binary Mixtures at 298.15 K
}

\author{
HARDEEP ANAND* and RENU VERMA \\ Department of Chemistry, Kurukshetra University, Kurukshetra, 136119, India \\ drhanandchem@gmail.com
}

Received 27 January 2018 / Accepted 3 March 2017

\begin{abstract}
Ultrasonic velocities $(u)$ and densities $(\rho)$ of $\mathrm{Me}_{4} \mathrm{NClO}_{4}, \mathrm{Et}_{4} \mathrm{NClO}_{4}, \mathrm{Pr}_{4} \mathrm{NClO}_{4}, \mathrm{Bu}_{4} \mathrm{NClO}_{4}$ and $\mathrm{Bu}_{4} \mathrm{NBPh}_{4}$ were measured at different salt concentrations in the range (30-500) $\times 10^{-4} \mathrm{~mol} \mathrm{~kg}^{-1}$ in binary mixtures of dimethylsulfoxide (DMSO) and methanol (MeOH) containing $0,20,40,50,60,80$ and $100 \mathrm{~mol} \%$ methanol at $298.15 \mathrm{~K}$. The isentropic compressibilities $\left(K_{s}\right)$ and apparent molal isentropic compressibilities $\left(K_{s, \phi}\right)$ of different salts in the binary solvent mixtures were calculated from ultrasonic velocity and density values. The apparent molal isentropic compressibilities $\left(K_{s, \phi}^{o}\right.$ ) of the salts were split into the contributions of individual ions $\left(K_{s, \phi}^{o}\right)_{ \pm}$. The ionic apparent molal isentropic compressibilities $\left(K_{s, \phi}^{o}\right)_{ \pm}$of $\mathrm{Bu}_{4} \mathrm{~N}^{+}$and $\mathrm{Ph}_{4} \mathrm{~B}^{-}$ are found to be positive which show strong solvophobic interactions in DMSO and in DMSO+MeOH mixtures over the entire solvent composition range. The negative values of $\mathrm{Me}_{4} \mathrm{~N}^{+}$ and $\mathrm{Et}_{4} \mathrm{~N}^{+}$ions have show strong structural effects which arise due to solute-solvent interactions in $\mathrm{MeOH}$ rich region of mixtures. The extent of solvation of tetraalkylammonium ions has been found to be in the order $\mathrm{Me}_{4} \mathrm{~N}^{+}>\mathrm{Et}_{4} \mathrm{~N}^{+}>\mathrm{Pr}_{4} \mathrm{~N}^{+}>\mathrm{Bu}_{4} \mathrm{~N}^{+}$in DMSO, MeOH and their binary mixtures.
\end{abstract}

Keywords: Compressibility, Solvation, Dimethylsulfoxide, Methanol, Tetraalkylammonium ions

\section{Introduction}

Ultrasonic velocity has been found to be the most powerful tools in understanding the solute-solvent interactions. Another useful property such as limiting apparent molal isentropic compressibility is an important parameter which not only provides the magnitude but also predicts the nature of the interactions on the basis of its values ${ }^{1}$. In the present work, ultrasonic velocity studies have been carried out on tetraalkylammonium salts in binary mixtures of dimethylsulfoxide (DMSO) and methanol $(\mathrm{MeOH})$. Ion-solvent interactions were extensively investigated in a number of mixed solvents using different techniques ${ }^{2,3}$. The aim of this work is to determine the solvation characteristic of $\mathrm{Bu}_{4} \mathrm{NClO}_{4}, \mathrm{Pr}_{4} \mathrm{NClO}_{4}$, $\mathrm{Et}_{4} \mathrm{NClO}_{4}$ and $\mathrm{Me}_{4} \mathrm{NClO}_{4}$ salts in the binary mixtures of DMSO and $\mathrm{MeOH}$ at $298.15 \mathrm{~K}$. 
This is determined from the apparent molal isentropic compressibilities $\left(K_{s, \phi}\right)$ which are calculated from the isentropic compressibilities $\left(K_{s}\right)$ of the salts. The previous investigations of the solvation of $\mathrm{Me}_{4} \mathrm{~N}^{+}, \mathrm{Et}_{4} \mathrm{~N}^{+}, \mathrm{Pr}_{4} \mathrm{~N}^{+}$and $\mathrm{Bu}_{4} \mathrm{~N}^{+}$ions are limited to 2-methoxyethanol, water $^{4}, N, N$-dimethylformamide, acetonitrile and $n$-butyronirile and their binary mixtures ${ }^{5}$. Mixtures of $\mathrm{DMSO}+\mathrm{MeOH}$ are therefore expected to be good solvents for a comparative study of the solvation behaviour of tetraalkylammonium ions. Both these solvents differ in dipole moment $(\mathrm{MeOH}=1.71 \mathrm{D} \text { and } \mathrm{DMSO}=3.90 \mathrm{D})^{6}$. Preferential solvation of ions has its application in hydrometallurgical purification of copper and silver ${ }^{7}$. Tetraalkylammonium salts exclusively find an application as electrolytes in developing supercapacitors also known as electrical double layer capacitors (EDLCs) ${ }^{8}$.

\section{Experimental}

Dimethylsulfoxide (DMSO) (Spectrochem) was dried over $4 \AA$ molecular sieves for 48 hours and then distilled from calcium hydride using $2 \times 15 \mathrm{~cm}$ vigreux column as reported ${ }^{9}$. A middle cut was taken, which have boiling point $57^{\circ} \mathrm{C}$ at 5 torr. Methanol (MeOH) (Hi-Media) was stored over $4 \AA$ molecular sieves for 48 hours and then purified by fractional distillation ${ }^{10-11}$. Methanol was dried over fused $\mathrm{CaCl}_{2}$ and then fractionally distilled over sodium. The density and ultrasonic velocity for purified solvents DMSO and $\mathrm{MeOH}$ were $1.09538 \mathrm{~g} \mathrm{~cm}^{-3}$, $0.78663 \mathrm{~g} \mathrm{~cm}^{-3}, 1494.97 \mathrm{~m} \mathrm{~s}^{-1}$ and $1102.0 \mathrm{~m} \mathrm{~s}^{-1}$ respectively and are reported in Table 1 .

The reference electrolyte tetrabutylammonium tetraphenylborate $\left(\mathrm{Bu}_{4} \mathrm{NBPh}_{4}\right)$ was prepared by mixing aqueous solutions of tetrabutylammonium bromide $\left(\mathrm{Bu}_{4} \mathrm{NBr}\right)$ and sodium tetraphenylborate $\left(\mathrm{NaBPh}_{4}\right)$ in $1: 1$ molar ratio. The aqueous solution of sodium tetraphenylborate was filtered before mixing in order to remove some suspension present in the solution. On mixing white precipitates formed was filtered and washed repeatedly with distilled water to remove the last traces of sodium tetraphenylborate. The prepared salt was purified by dissolving in minimum quantity of acetone and reprecipitated out by adding excess of distilled water. The procedure was repeated twice. Finally the salt was filtered and dried at $60{ }^{\circ} \mathrm{C}$ under vacuum over phosphorous pentoxide $\left(\mathrm{P}_{2} \mathrm{O}_{5}\right)$ for two days. The melting point of salt was found to be $223-224{ }^{\circ} \mathrm{C}$, which was in good agreement with the value reported in literature ${ }^{12}\left(222-225^{\circ} \mathrm{C}\right)$. Tetraalkylammonium perchlorates $\left(\mathrm{R}_{4} \mathrm{NClO}_{4}\right)$ were prepared by mixing aqueous solution of tetraalkylammonium hydroxide $\left(\mathrm{R}_{4} \mathrm{NOH}\right.$, Himedia, $40 \%)$ and perchloric acid $\left(\mathrm{HCIO}_{4}\right.$, Merck, $\left.70 \%\right)$ in 1:1 molar ratio. On mixing white precipitates were formed and filtered. The prepared salt was purified by dissolving in minimum quantity of acetone and reprecipitated out by adding excess of distilled water. The process was repeated twice. Finally the salts were filtered and dried at $60{ }^{\circ} \mathrm{C}$ under vacuum over phosphorous pentoxide $\left(\mathrm{P}_{2} \mathrm{O}_{5}\right)$ for two days.

Table 1. Permittivity $(\varepsilon)$, density $(\rho)$, ultrasonic velocity $(u)$ and isentropic compressibility $\left(K_{s}\right)$ for $\mathrm{DMSO}+\mathrm{MeOH}$ mixtures at $298.15 \mathrm{~K}$

\begin{tabular}{ccccc}
\hline $\mathrm{mol} \% \mathrm{MeOH}$ & $(\varepsilon)$ & $\rho / \mathrm{g} \mathrm{cm}^{-3}$ & $u / \mathrm{m} \mathrm{s}^{-1}$ & $10^{6} K_{s} / \mathrm{bar}^{-1}$ \\
\hline 0 & 47.22 & 1.095389 & 1494.97 & 40.84 \\
20 & 45.49 & 1.080889 & 1399.94 & 47.20 \\
40 & 42.58 & 1.050099 & 1303.99 & 56.00 \\
50 & 40.87 & 1.012234 & 1259.99 & 62.22 \\
60 & 37.09 & 0.933201 & 1188.33 & 75.87 \\
80 & 35.44 & 0.895513 & 1121.93 & 88.71 \\
100 & 32.60 & 0.786637 & 1102.03 & 104.67 \\
\hline
\end{tabular}


A range of concentrations of the salts in $\mathrm{DMSO}, \mathrm{MeOH}$ and $\mathrm{DMSO}+\mathrm{MeOH}$ mixtures were prepared by diluting stock solutions of appropriate concentrations. The mixtures were prepared by mass using an A and D limited electronic balance (Japan, Model GR-202) with precision of $\pm 0.01 \mathrm{mg}$ and were kept in air tight stoppered glass bottles to avoid the absorption of atmospheric moisture. The probable error in the molality was found to be less than $\pm 1 \times 10^{-4} \mathrm{~mol} \mathrm{~kg}^{-1}$. Before the measurement of any series of the solutions, the instrument was calibrated with triple-distilled freshly degassed water and dry air at atmospheric pressure. Ultrasonic velocity and density measurements of binary mixtures as well as of the salt solutions were carried out using Anton Paar digital densimeter (model DSA 5000) operated in the static mode and automatically thermostated within $\pm 0.001 \mathrm{~K}$. The densities and ultrasonic velocity had precision better than $\pm 1 \times 10^{-6} \mathrm{~g} \mathrm{~cm}^{-3}$ and $\pm 1 \times 10^{-2} \mathrm{~m} \mathrm{~s}^{-1}$ respectively. The uncertainties in the solution density and ultrasonic velocity were found to be better than $\pm 5 \times 10^{-6} \mathrm{~g} \mathrm{~cm}^{-3}$ and $\pm 5 \times 10^{-2} \mathrm{~m} \mathrm{~s}^{-1}$ respectively ${ }^{13}$.

\section{Results and Discussion}

\section{Compressibility studies}

Ultrasonic velocities $(u)$ and densities $(\rho)$ of $\mathrm{Me}_{4} \mathrm{NClO}_{4}, \mathrm{Et}_{4} \mathrm{NclO}_{4}, \mathrm{Pr}_{4} \mathrm{NclO}_{4}, \mathrm{Bu}_{4} \mathrm{NclO}_{4}$ and $\mathrm{Bu}_{4} \mathrm{NBPh}_{4}$ were measured at different salt concentrations in the range $(30-500) \times 10^{-4} \mathrm{~mol} \mathrm{~kg}^{-1}$ in binary mixtures of dimethylsulfoxide (DMSO) and methanol $(\mathrm{MeOH})$ containing $0,20,40,50,60,80$ and $100 \mathrm{~mol} \% \mathrm{MeOH}$ at $298.15 \mathrm{~K}$. The isentropic compressibilities $\left(K_{s}\right)$ of solutions were calculated from the relation

$$
K_{s}=\frac{1}{u^{2} \rho}
$$

Using partial molal volume $\left(V_{\phi}\right)$, the apparent molal isentropic compressibility $\left(K_{s, \phi}\right)$ of the electrolytes were evaluated using the following relations

$$
\begin{aligned}
V_{\phi} & =\frac{M}{\rho}-\frac{10^{3}\left[\rho-\rho_{o}\right]}{m \rho \rho_{o}} \\
K_{s, \phi} & =V_{\phi} K_{s}+\frac{10^{3}\left[K_{s}-K_{o}\right]}{m \rho_{o}}
\end{aligned}
$$

Where $m$ and $M$ are molality and molecular mass of the solute, $K_{s}$ and $K_{o}$ are the isentropic compressibility of the solution and solvent mixtures and $\rho_{o}$ and $\rho$ are the densities of solvent and solution mixtures respectively. Figure 1 to 7 shows the plots of $K_{s, \phi}$ versus $m^{1 / 2}$. The limiting apparent molal $\left(K_{s, \phi}^{o}\right)_{ \pm}$isentropic compressibilities were obtained by extrapolation of the linear plots of $K_{s, \phi}$ versus $m^{1 / 2}$ by the least square method using equation

$$
K_{s, \phi}=K_{s, \phi}^{o}+A_{s, \phi} m^{1 / 2}
$$

When the ultrasonic waves are incident on the solution, the molecules get perturbed. Since the medium has some elasticity and hence perturbed molecules regain their equilibrium positions. When a solute is added to a solvent, its molecules attract certain solvent molecules towards them. This phenomenon is known as compression. Every solvent has a limit for compression and is known as limiting compressibility. 


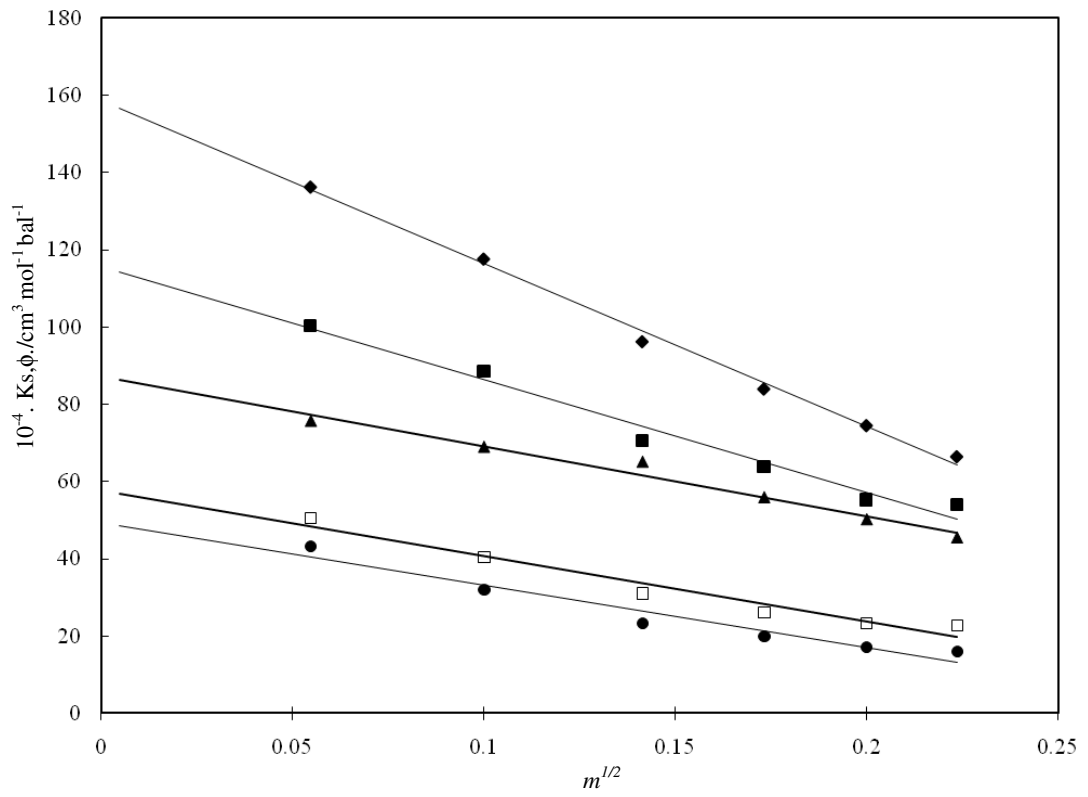

Figure 1. Plots of $K s \phi$, vs $m^{1 / 2}$ in DMSO at 298.15.K, $-\mathrm{Bu}_{4} \mathrm{NBPh}_{4},-\mathbf{-}-\mathrm{Bu}_{4} \mathrm{NCIO}_{4}$, $\Delta-\mathrm{Pr}_{4} \mathrm{NCIO}_{4}, \square-\mathrm{Et}^{4} \mathrm{NCIO}_{4}, \bullet-\mathrm{Me}_{4} \mathrm{NCIO}_{4}$

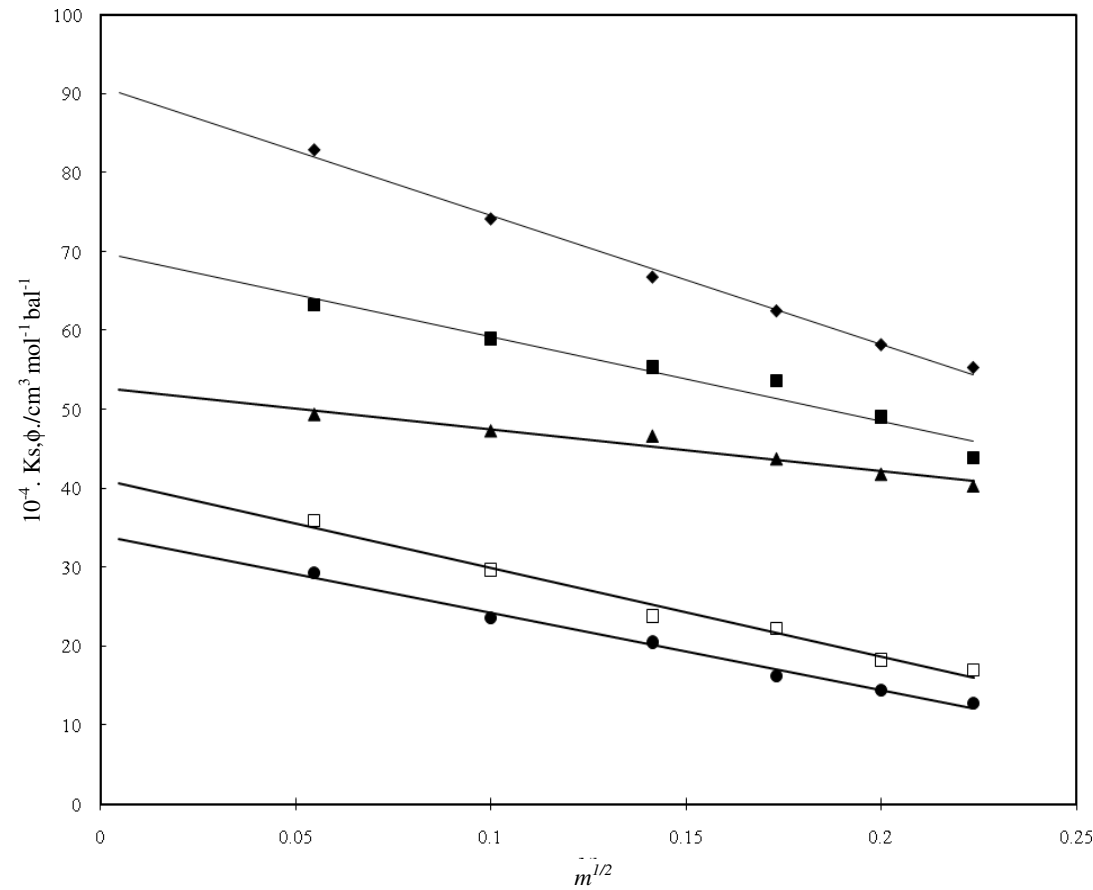

Figure 2. Plots of $K s \phi$, vs $m^{1 / 2}$ in $20 \mathrm{~mol} \% \mathrm{MeOH}$ in DMSO at 298.15.K, $-\mathrm{Bu}_{4} \mathrm{NBPh}_{4}$, - $-\mathrm{Bu}_{4} \mathrm{NCIO}_{4}, \boldsymbol{\Delta}-\mathrm{Pr}_{4} \mathrm{NCIO}_{4}, \square-\mathrm{Et}^{4} \mathrm{NCIO}_{4}, \bullet-\mathrm{Me}_{4} \mathrm{NCIO}_{4}$ 


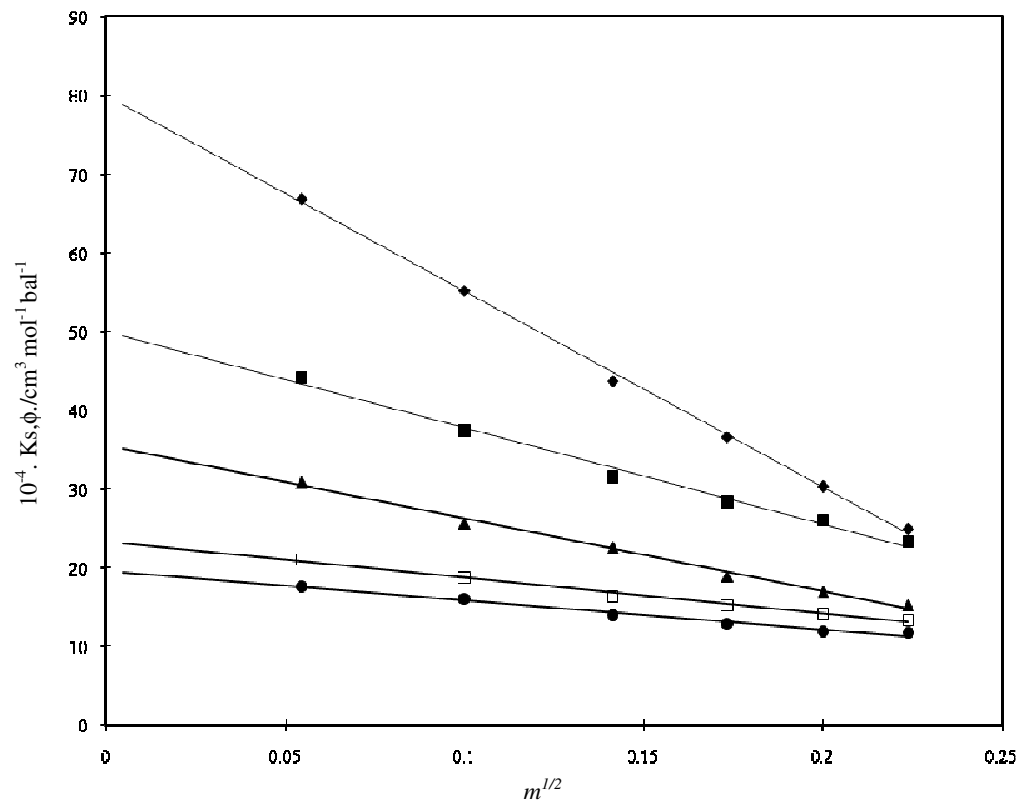

Figure 3. Plots of $K s \phi$, vs $m^{1 / 2}$ in $40 \mathrm{~mol} \% \mathrm{MeOH}$ in DMSO at 298.15.K, $-\mathrm{Bu}_{4} \mathrm{NBPh}_{4}$, - $-\mathrm{Bu}_{4} \mathrm{NCIO}_{4}, \boldsymbol{\Delta}-\mathrm{Pr}_{4} \mathrm{NCIO}_{4}, \square-\mathrm{Et}^{4} \mathrm{NCIO}_{4}, \bullet-\mathrm{Me}_{4} \mathrm{NCIO}_{4}$

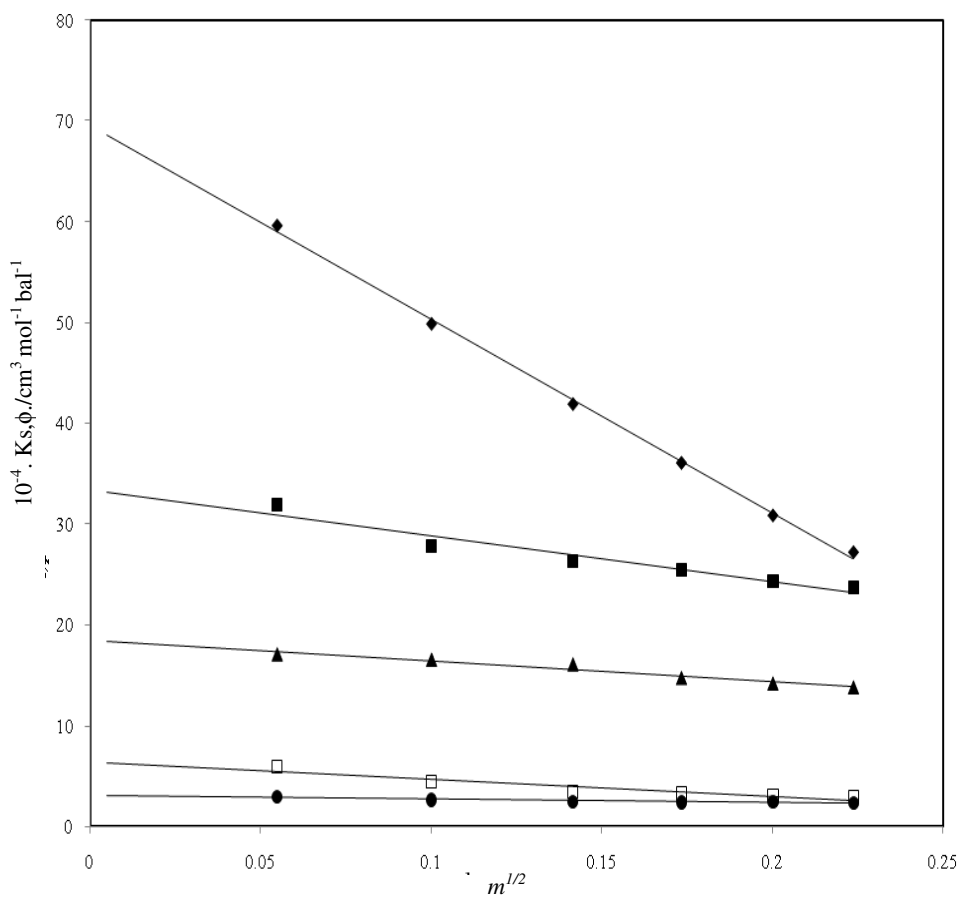

Figure 4. Plots of $K s \phi$, vs $m^{1 / 2}$ in $50 \mathrm{~mol} \% \mathrm{MeOH}$ in DMSO at 298.15.K, $-\mathrm{Bu}_{4} \mathrm{NBPh}_{4}$, - $-\mathrm{Bu}_{4} \mathrm{NCIO}_{4}, \boldsymbol{\Delta}-\mathrm{Pr}_{4} \mathrm{NCIO}_{4}, \square-\mathrm{Et}^{4} \mathrm{NCIO}_{4}, \bullet-\mathrm{Me}_{4} \mathrm{NCIO}_{4}$ 


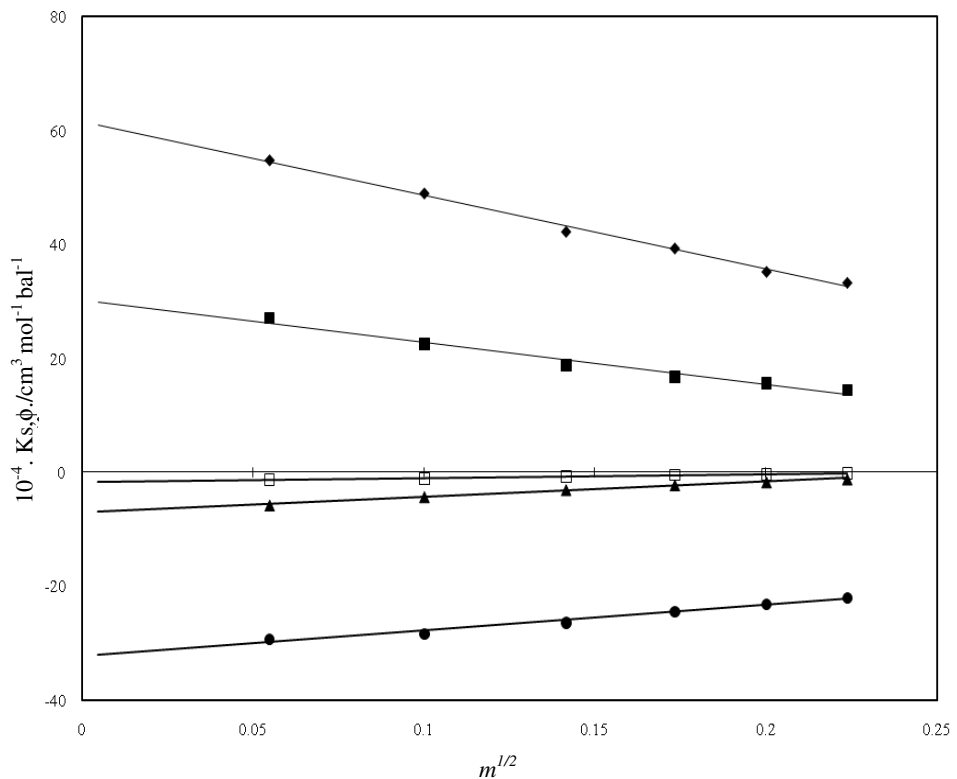

Figure 5. Plots of Ks $\phi$, vs. $m^{1 / 2}$ in $60 \mathrm{~mol} \% \mathrm{MeOH}$ in DMSO at 298.15.K, $-\mathrm{Bu}_{4} \mathrm{NBPh}_{4}$, $\mathrm{Bu}_{4} \mathrm{NCIO}_{4}, \boldsymbol{\Delta}-\mathrm{Pr}_{4} \mathrm{NCIO}_{4}, \square-\mathrm{Et}^{4} \mathrm{NCIO}_{4}, \bullet-\mathrm{Me}_{4} \mathrm{NCIO}_{4}$

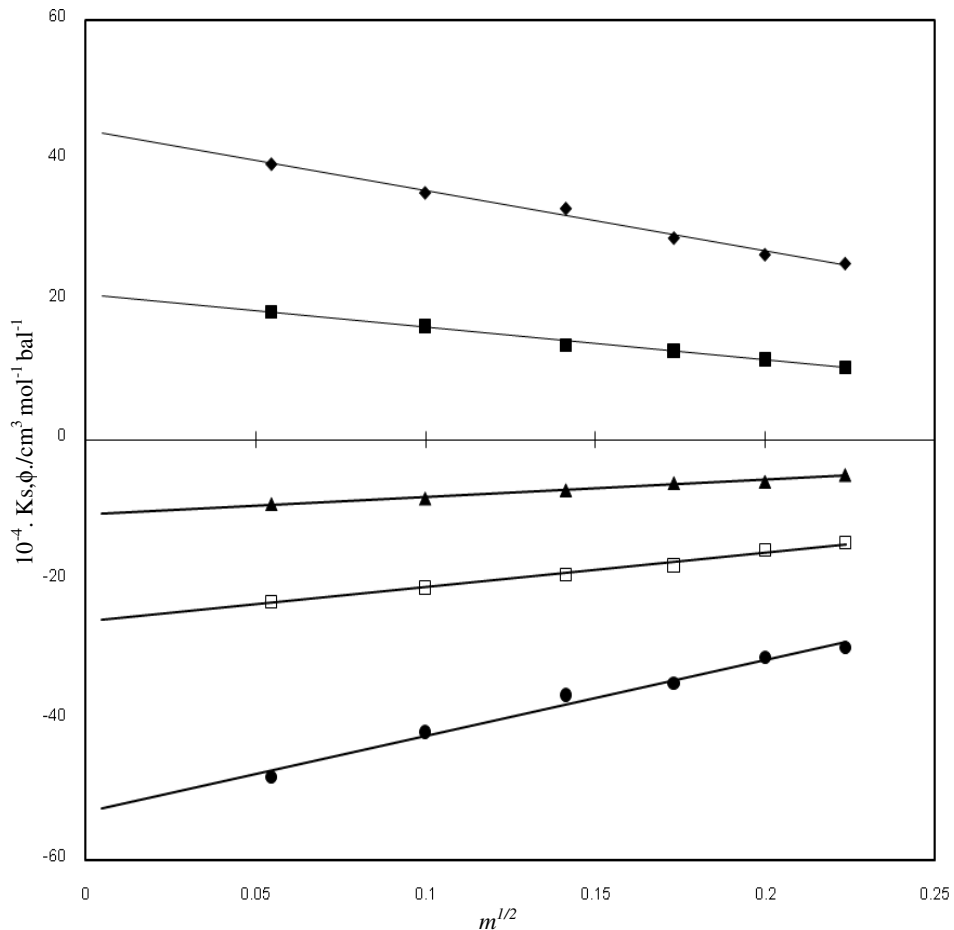

Figure 6. Plots of Ks $\phi$, vs. $m^{1 / 2}$ in $80 \mathrm{~mol} \% \mathrm{MeOH}$ in DMSO at 298.15.K, $-\mathrm{Bu}_{4} \mathrm{NBPh}_{4}$, $\mathrm{Bu}_{4} \mathrm{NCIO}_{4}, \boldsymbol{\Delta}-\mathrm{Pr}_{4} \mathrm{NCIO}_{4}, \square-\mathrm{Et}^{4} \mathrm{NCIO}_{4}, \bullet-\mathrm{Me}_{4} \mathrm{NCIO}_{4}$ 


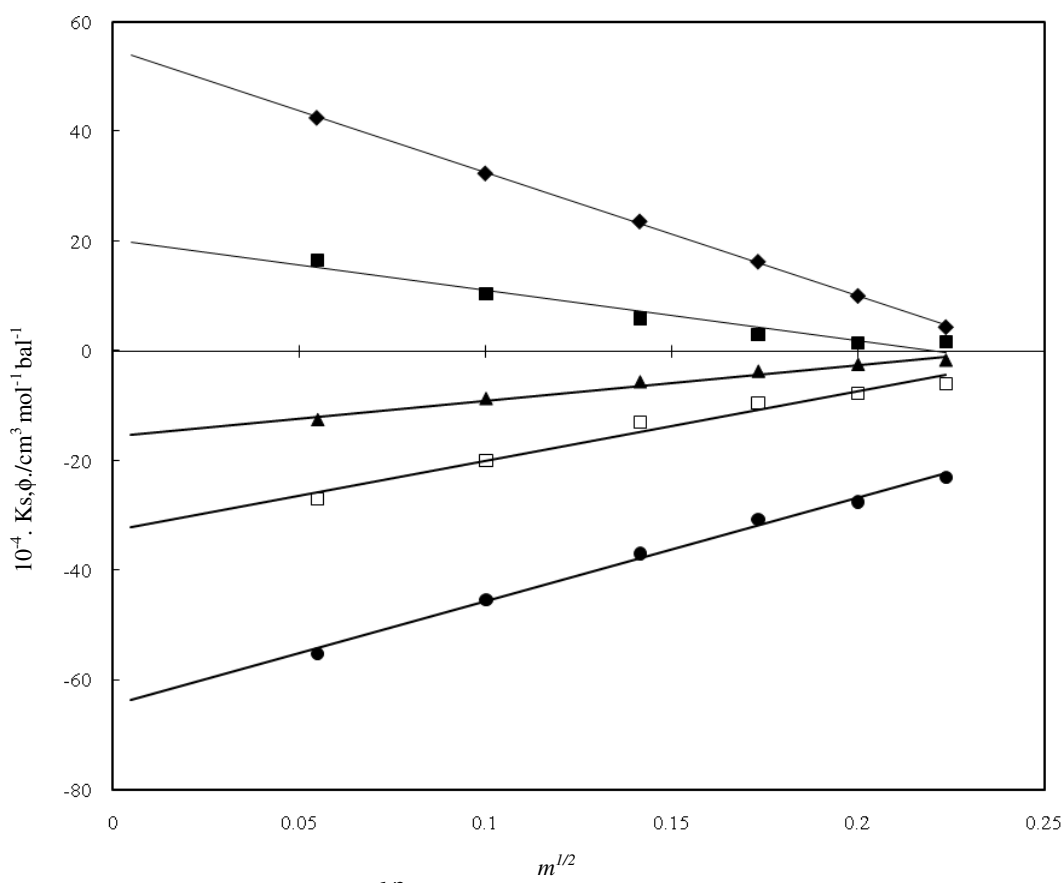

Figure 7. Plots of Ks $\phi$, vs. $m^{1 / 2}$ in Methanol at 298.15.K, $-\mathrm{Bu}_{4} \mathrm{NBPh}_{4},-\mathrm{Bu}_{4} \mathrm{NCIO}_{4}$, $\boldsymbol{\Delta}-\mathrm{Pr}_{4} \mathrm{NCIO}_{4}, \square-\mathrm{Et}^{4} \mathrm{NCIO}_{4}, \bullet-\mathrm{Me}_{4} \mathrm{NCIO}_{4}$

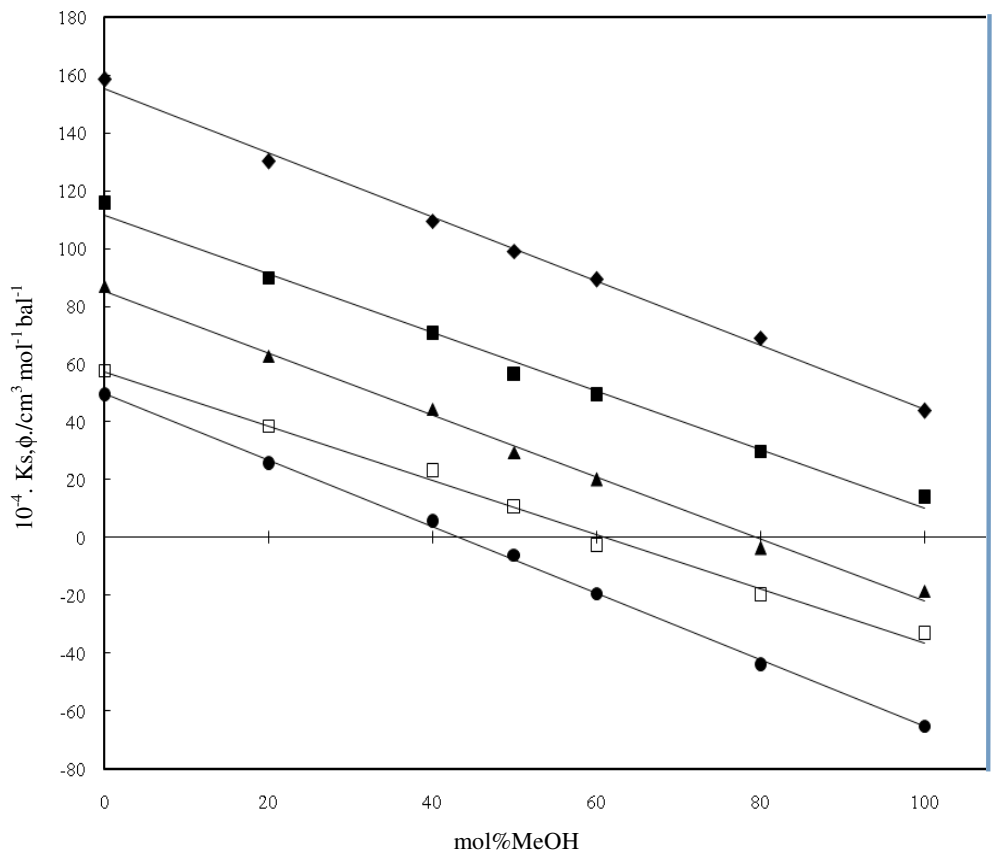

Figure 8. Plots of Ks $\phi$, vs. mol\% $\mathrm{MeOH}$ in $\mathrm{DMSO}$ at 298.15.K, $-\mathrm{Bu}_{4} \mathrm{NBPh}_{4}, \mathbf{m}-\mathrm{Bu}_{4} \mathrm{NCIO}_{4}$, $\Delta-\mathrm{Pr}_{4} \mathrm{NCIO}_{4}, \square-\mathrm{Et}^{4} \mathrm{NCIO}_{4}, \bullet-\mathrm{Me}_{4} \mathrm{NCIO}_{4}$ 
Table 2 shows $K_{s, \phi}^{o}$ values for various salts. The plot of limiting apparent molal isentropic compressibilities $K_{s, \phi}^{o}$ for $\mathrm{Me}_{4} \mathrm{NClO}_{4}, \mathrm{Et}_{4} \mathrm{NClO}_{4}, \mathrm{Pr}_{4} \mathrm{NClO}_{4}, \mathrm{Bu}_{4} \mathrm{NClO}_{4}$ and $\mathrm{Bu}_{4} \mathrm{NBPh}_{4}$ vs. mol\% MeOH at $298.15 \mathrm{~K}$ is shown in Figure 8. Since the plots are not curved in any case, this indicates the non-formation of ion-pairs of the salts. The linearity of the plots in most of the cases show that all the electrolytes are not associated in DMSO+MeOH mixture over the salt concentrations studied. The $K_{s, \phi}^{o}$ values for $\mathrm{Bu}_{4} \mathrm{NBPh}_{4}$ and $\mathrm{Bu}_{4} \mathrm{NClO}_{4}$ were positive and decrease in magnitude with an increase in mole fraction of $\mathrm{MeOH}$. The negative $K_{s, \phi}^{o}$ values after $50 \mathrm{~mol} \% \mathrm{MeOH}$ for $\mathrm{Pr}_{4} \mathrm{NClO}_{4}, \mathrm{Et}_{4} \mathrm{NClO}_{4}$ and $\mathrm{Me}_{4} \mathrm{NClO}_{4}$ indicate strong solvation effects in $\mathrm{DMSO}+\mathrm{MeOH}$ binary mixtures.

Table 2. Limiting apparent molal isentropic compressibility ( $K_{s, \phi}^{o}$ ) of some salts in solvent mixtures of $\mathrm{DMSO}+\mathrm{MeOH}$ at $298.15 \mathrm{~K}$

\begin{tabular}{cccccccc}
\hline \multicolumn{7}{c}{$10^{-4} .\left(K_{s, \phi}^{o}\right) / \mathrm{cm}^{3} \mathrm{~mol}^{-1} \mathrm{bar}^{-1}$} \\
\hline salts & 0 & 20 & 40 & 50 & 60 & 80 & 100 \\
\hline $\mathrm{Bu}_{4} \mathrm{NBPh}_{4}$ & 158.5 & 88.22 & 73.41 & 67.09 & 60.00 & 44.13 & 43.88 \\
$\mathrm{Bu}_{4} \mathrm{NClO}_{4}$ & $158)$ & & & & & & \\
$\mathrm{Pr}_{4} \mathrm{NClO}_{4}$ & 87.07 & 59.87 & 50.45 & 33.38 & 30.32 & 20.75 & 16.85 \\
$\mathrm{Et}_{4} \mathrm{NClO}_{4}$ & 57.74 & 39.72 & 34.45 & 18.45 & -1.804 & -10.61 & -15.49 \\
$\mathrm{Me}_{4} \mathrm{NClO}_{4}$ & 49.22 & 32.53 & 19.26 & 6.40 & -19.90 & -26.02 & -33.37 \\
\multicolumn{7}{c}{ Maximum uncertainty in these values is $\pm 2.6 \times 10^{-4} \mathrm{~m}^{3} \mathrm{~mol}^{-1}$ bar $^{-1}$} &
\end{tabular}

\section{Limiting ionic apparent molal isentropic compressibilities}

The $K_{s, \phi}^{o}$ values are additive ${ }^{14}$ and can be directly split into the contributions of individual ions to obtain structural or solvation effects. The $K_{s, \phi}^{o}$ values for the salt from Table 2 were split into the contributions of the individual ions. Millero split the partial molar volume of electrolyte into ionic components using $\mathrm{Bu}_{4} \mathrm{AsBPh}_{4}$ as a reference electrolyte ${ }^{15}$. Gill and coworkers suggested a model ${ }^{7}$, in which use of the reference electrolyte $\mathrm{Bu}_{4} \mathrm{NBPh}_{4}$ was recommended to split $K_{s, \phi}^{o}$ values into its ionic contributions $\left(K_{s, \phi}^{o}\right)_{ \pm}$with the help of following equations

$$
\begin{gathered}
\frac{K_{s, \phi}^{o}\left(B u_{4} \mathrm{~N}^{+}\right)}{K_{\phi}^{o}\left(P h_{4} B^{-}\right)}=\frac{r_{c}^{3}\left(B u_{4} \mathrm{~N}^{+}\right)}{r_{c}^{3}\left(P h_{4} B^{-}\right)}=\frac{(5.00)^{3}}{(5.35)^{3}} \\
K_{s, \phi}^{o}\left(B u_{4} \mathrm{~N} B \mathrm{Ph}_{4}\right)=K_{s, \phi}^{o}\left(B u_{4} \mathrm{~N}^{+}\right)+K_{s, \phi}^{o}\left(P h_{4} B^{-}\right)
\end{gathered}
$$

Where $r_{c}$ refers to the crystallographic radius of the ions. Using equations (5) and (6), $K_{s, \phi}^{o}$ values for $\mathrm{Bu}_{4} \mathrm{NBPh}_{4}$ were split into the ionic contribution for $\mathrm{Bu}_{4} \mathrm{~N}^{+}$and $\mathrm{Ph}_{4} \mathrm{~B}^{-}$ions. By using these values, $\left(K_{s, \phi}^{o}\right)_{ \pm}$for $\mathrm{Pr}_{4} \mathrm{~N}^{+}, \mathrm{Et}_{4} \mathrm{~N}^{+}$and $\mathrm{Me}_{4} \mathrm{~N}^{+}$were calculated on the basis of 
additive principle and are reported in Table 3. The negative values of $\left(K_{s, \phi}^{o}\right)_{ \pm}$for $\operatorname{Pr}_{4} \mathrm{~N}^{+}$, $\mathrm{Et}_{4} \mathrm{~N}^{+}$and $\mathrm{Me}_{4} \mathrm{~N}^{+}$are generally obtained after $50 \mathrm{~mol} \% \mathrm{MeOH}$ due to stronger solvation effects (ion-solvent interactions) while positive values of $\mathrm{Ph}_{4} \mathrm{~B}^{-}, \mathrm{Bu}_{4} \mathrm{~N}^{+}$are obtained due to special interactions (hydrophobic or dispersive interactions). The special interaction of $\mathrm{Ph}_{4} \mathrm{~B}^{-}$with DMSO was also reported by Joana and Dorota ${ }^{16}$. The plot of limiting ionic apparent molal isentropic compressibilities $\left(K_{s, \phi}^{o}\right)_{ \pm}$for $\mathrm{Ph}_{4} \mathrm{~B}^{-}, \mathrm{Bu}_{4} \mathrm{~N}^{+}, \mathrm{Pr}_{4} \mathrm{~N}^{+}, \mathrm{Et}_{4} \mathrm{~N}^{+}$and $\mathrm{Me}_{4} \mathrm{~N}^{+}$ vs. $\mathrm{mol} \% \mathrm{MeOH}$ at $298.15 \mathrm{~K}$ is shown in Figure 9. The extent of interactions between a small cation and the free electron pair of oxygen is found to be greater in $\mathrm{MeOH}$ than in DMSO resulting in more solvation and consequently, lower mobilities in $\mathrm{MeOH}$ solutions. The charge dipole interactions predominates as the size of cation increases which results increases the distance of close approach of cation and solvent molecule.

Table 3. Limiting ionic apparent molal isentropic compressibility $\left(K_{s, \phi}^{o}\right)_{ \pm}$for some ions in DMSO+MeOH mixtures at $298.15 \mathrm{~K}$

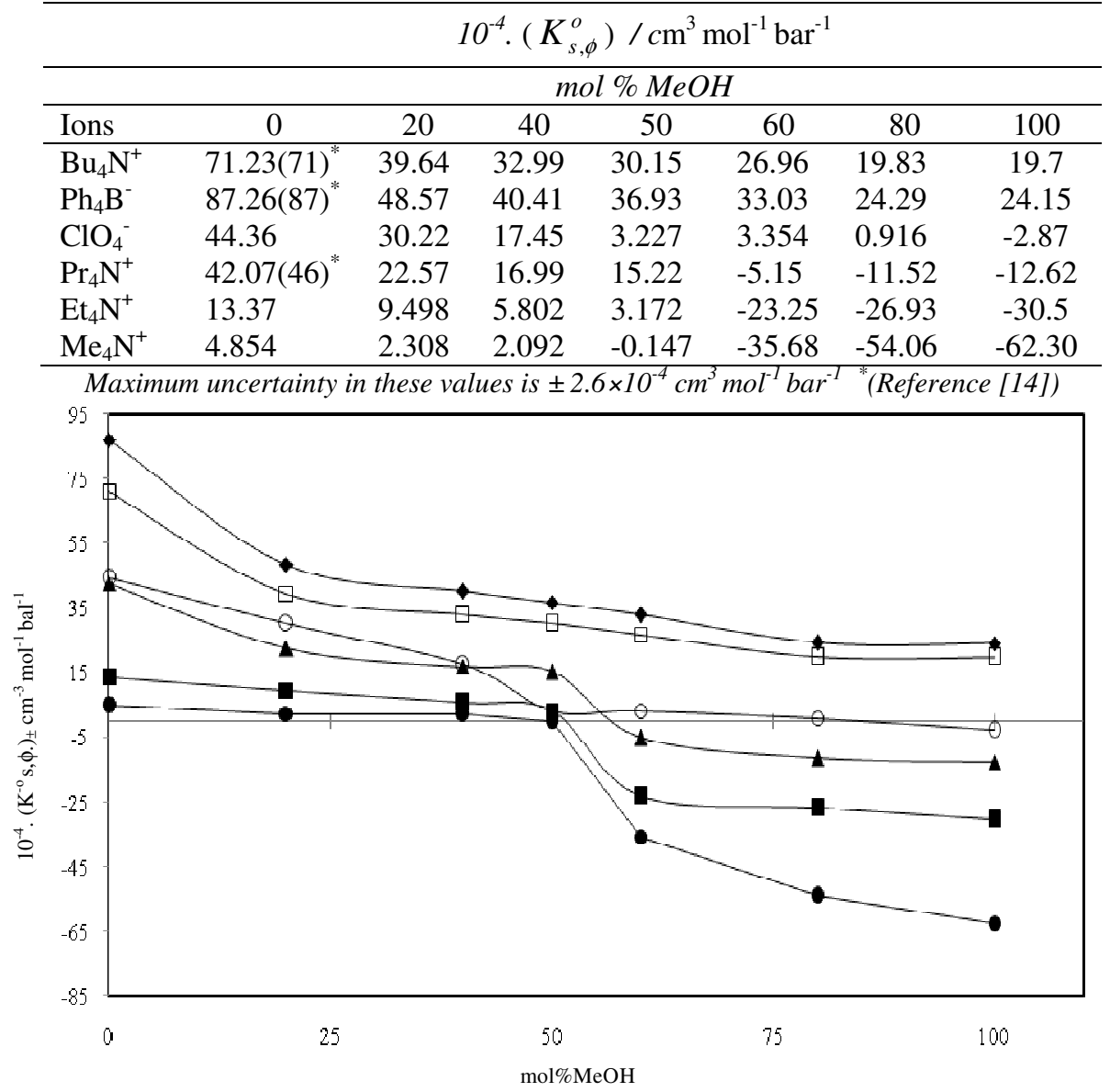

Figure 9. Plots of $\left(K_{s, \phi}^{o}\right)_{ \pm}$versus mol\% of methanol im DMSO+MeOH mixtures at 298.15.K, $\square-\mathrm{Bu}_{4} \mathrm{~N}^{+}, \boldsymbol{\Delta}-\mathrm{Pr}_{4} \mathrm{~N}^{+}, \boldsymbol{-}-\mathrm{Et}^{4} \mathrm{~N}^{+}, \bullet-\mathrm{Me}_{4} \mathrm{~N}^{+},-\mathrm{Ph}_{4} \mathrm{~B}^{-}, \mathrm{O}-\mathrm{ClO}_{4}^{-}$ 
After $50 \mathrm{~mol} \% \mathrm{MeOH},\left(K_{s, \phi}^{o}\right)_{ \pm}$values become more negative with increase in $\mathrm{MeOH}$ composition suggesting that the extent of solvation increases with an increase in $\mathrm{MeOH}$ composition. Thus it appears that as the size of cations becomes small, the availability of a free electron pair in the $\mathrm{MeOH}$ molecule determines solvation effects to a great extent. The larger perchlorate ion is not affected by the acid properties of the solvent, but, if at all, its solvation sheath is determined by the larger dipole moment of DMSO compared to $\mathrm{MeOH}$. Thus from the results it would appear that acid-base properties of the solvent molecules measures the degree of solvation of large ions.

\section{Conclusion}

The tetraalkylammonium ions do not appear to interact strongly with pure DMSO. All tetraalkylammonium salts appear to be completely dissociated in the experimental concentration range. This provides a clue that their ions neither promote nor break the structure of DMSO. This may be due to a simple reason that there is no hydrogen-bonded structure present in the pure solvent. The negative $\left(K_{s, \phi}^{o}\right)_{ \pm}$values for $\mathrm{Me}_{4} \mathrm{~N}^{+}, \mathrm{Et}_{4} \mathrm{~N}^{+}$and $\operatorname{Pr}_{4} \mathrm{~N}^{+}$indicate strong ion-solvent interactions and hence, preferential solvation in $\mathrm{MeOH}-$ rich region of the $\mathrm{DMSO}+\mathrm{MeOH}$ binary mixtures. The positive values for $\mathrm{Bu}_{4} \mathrm{~N}^{+}$and $\mathrm{Ph}_{4} \mathrm{~B}^{-}$indicate some special type of interactions with the solvent molecules, possibly solvophobic, which decrease with the increase of $\mathrm{MeOH}$ composition in the binary mixtures. The negative $\left(K_{s, \phi}^{o}\right)_{ \pm}$values for $\mathrm{Me}_{4} \mathrm{~N}^{+}, \mathrm{Et}_{4} \mathrm{~N}^{+}$and $\mathrm{Pr}_{4} \mathrm{~N}^{+}$increase with increase in $\mathrm{MeOH}$ composition suggest that their extent of solvation also increases. Since both the solvents differ considerably in their basicity and dipole moment, so a comparative solvation of the ions has been observed at different solvent composition range. The solvation of the tetraalkylammonium ions follows the order $\mathrm{Me}_{4} \mathrm{~N}^{+}>\mathrm{Et}_{4} \mathrm{~N}^{+}>\mathrm{Pr}_{4} \mathrm{~N}^{+}>\mathrm{Bu}_{4} \mathrm{~N}^{+}$in DMSO+MeOH binary mixtures at all compositions.

\section{References}

1. Gill D S, Anand H and Pathania V, Z Phys Chem., 2004, 218, 857-865.

2. Gill D S, Rodehueser L, Rubini P and Delpuech J J, J Chem Soc Faraday Trans., 1995, 91, 2307; DOI:10.1039/FT9959102307

3. Gill D S, Kemp U, Dölle A and Zeidler M D, Indian J Chem., 2001, 40A, 693-699.

4. Das B and Hazra D K, J Chem Engg Data, 1996, 41(6), 1470-1472; DOI:10.1021/je9601974

5. Gill D S, Kumari A, Kumar S and Jauhar S P, Z Naturforsch., 2005, 60A, 70-74.

6. Kratochvil B and Yeager H L, Topic in Current Chemistry, Springer, Heidelberg 1972, 27, 1.

7. Gill D S and Sharma A N, J Chem Soc Faraday Trans., 1982, 78, 475-484; DOI:10.1039/F19827800475

8. Appleby A J, Velev O A, LeHelloco J G, Parthasarthy A, Srinivasan S, DesMarteau D D, Gillette M S and Ghosh J K, J Electrochem Soc., 1993, 140(1), 109-111; DOI:10.1149/1.2056068

9. Jackson M D and Gilkerson W R, J Am Chem Soc., 1979, 101(2), 328-333; https://doi.org/10.1021/ja00496a009

10. Das B, Nirmal Saha and Hazara D K, J Chem Engg Data, 2000, 45(2), 353-357; DOI:10.1021/je990239z 
11. Gill D S and Bakshi M S, J Chem Soc., Faraday Trans. 1., 1988, 84(10), 3517-3528; http://dx.doi.org/DOI:10.1039/F19888403517

12. Riddick J A, Bunger W B and Sakano T K Organic Solvents, Physical Properties and Methods of Purification, Wiley Interscience, New York, $4^{\text {th }}$ Edition, 1986.

13. Krakowiak J, Bobicz D and Grzybkowski W, J Chem Therm., 2001, 33(1), 121-133; DOI:10.1006/jcht.2000.0725

14. Chauhan S, Kumari U, Chauhan M S and Syal V K, J Mol Liq., 2007, 136(1-2), 2-4; DOI:10.1016/j.molliq.2006.12.032

15. Gill D S, Rana D S and Jauhar S P, J Chem Engg Data, 2010, 55(5), 2066-2701; DOI:10.1021/je900915p

16. Bicknell R T M, Lawrence K G, Seeley M A, Feakins D and Werblan L, J Chem Soc. Faraday Trans., I, 1976, 72, 307-313; DOI:10.1039/F19767200307 